Jesús Delgado-Domínguez: None declared, Denis Poddubnyy Grant/research support from: AbbVie, MSD, Novartis, and Pfizer, Consultant of: AbbVie, Bristol-Myers Squibb, Eli Lilly, MSD, Novartis, Pfizer, Roche, UCB, Speakers bureau: AbbVie, Bristol-Myers Squibb, Eli Lilly, MSD, Novartis, Pfizer, Roche, UCB DOI: 10.1136/annrheumdis-2020-eular.4221

OP0279

\section{THE IMPACT OF A REFERRAL STRATEGY FOR AXIAL SPONDYLOARTHRITIS: 12 MONTHS FOLLOW-UP OF PATIENT REPORTED OUTCOMES}

M. J. Abdelkadir ${ }^{1}$, M. Kuijper ${ }^{1}$, C. Appels ${ }^{2}$, A. Spoorenberg ${ }^{3}$, J. Hazes ${ }^{4}$, L. Van Hoeven ${ }^{4}$, D. Lopes Barreto ${ }^{1}$, A. Weel ${ }^{1,5} .{ }^{1}$ Maasstadziekenhuis, Rotterdam, Netherlands; ${ }^{2}$ Amphia Hospital, Breda, Netherlands; ${ }^{3}$ University Medical Center Groningen, Groningen, Netherlands: ${ }^{4}$ Erasmus Medical Center, Rotterdam, Netherlands; ${ }^{5}$ Erasmus School of Health Policy \& Management (ESHPM), Rotterdam, Netherlands

Background: Early recognition of axial spondyloarthritis (axSpA) patients is difficult for general practitioners within the large amount of chronic low back pain (CLBP) patients ${ }^{1}$. As a result, several referral strategies have been developed to help physicians identify patients at risk for axSpA. Most referral strategies were developed in secondary care patients with no available data on their impact. The only referral strategy that was developed and validated in primary CLBP patients is the Case Finding Axial Spondyloarthritis (CaFaSpA) strategy, but required an impact analysis before implementation in daily clinical practice ${ }^{2-3}$.

Objectives: The purpose of this study was to assess the impact of using the $\mathrm{CaFaSpA}$ referral strategy on patient reported outcome outcomes (PROs) in primary care patients with CLBP at risk for axSpA.

Methods: A clustered randomized controlled trial was performed in a primary care setting in the Netherlands. (ClinicalTrials.gov Identifier: NCT01944163). Each cluster contained the general practices from a single primary care practice and their included patients. Clusters were randomized to either the intervention (use of $\mathrm{CaFaSpA}$ referral strategy) or the control group (usual care). Primary outcome was disability after 12 months. Secondary outcome was quality of life, pain and fatigue after 12 months. A linear mixed-effects model was used to explore the effects over time according to intention to treat analysis.

Results: In total 679 patients were included within 93 GP clusters. Sixty-four percent of our study population were female and mean age was 36 (7.5) years. Overall RMDQ reduced over time both in the intervention and control group (figure 1). The difference in decrease was not statically significant between the groups (p-value 0.81 ).

EQ-5D increased by 0.03 after 12 months within the intervention group and 0.01 in the control group (not significant) (table 1). The decrease in pain and fatigue did not differ significantly between the intervention and control group.

Table 1. Mean change in PROs after 12 months in the intervention and control group

\begin{tabular}{|c|c|c|c|c|c|c|}
\hline \multirow[t]{2}{*}{ PROs } & \multicolumn{3}{|c|}{ Intervention } & \multicolumn{3}{|c|}{ Usual care } \\
\hline & Baseline & 12 months & $p$-value & Baseline & 12 months & p-value \\
\hline EQ-5D mean (SD) & $0.69(0.26)$ & $0.72(0.27)$ & 0.14 & $0.72(0.24)$ & $0.73(0.25)$ & 0.53 \\
\hline VAS-pain mean (SD) & $5.03(2.42)$ & $4.68(2.69)$ & 0.07 & $4.96(2.42)$ & 4.55 (2.69) & 0.02 \\
\hline VAS-fatigue mean (SD) & $5.19(2.50)$ & $5.01(0.21)$ & 0.35 & $5.23(2.45)$ & $4.86(2.73)$ & 0.04 \\
\hline
\end{tabular}

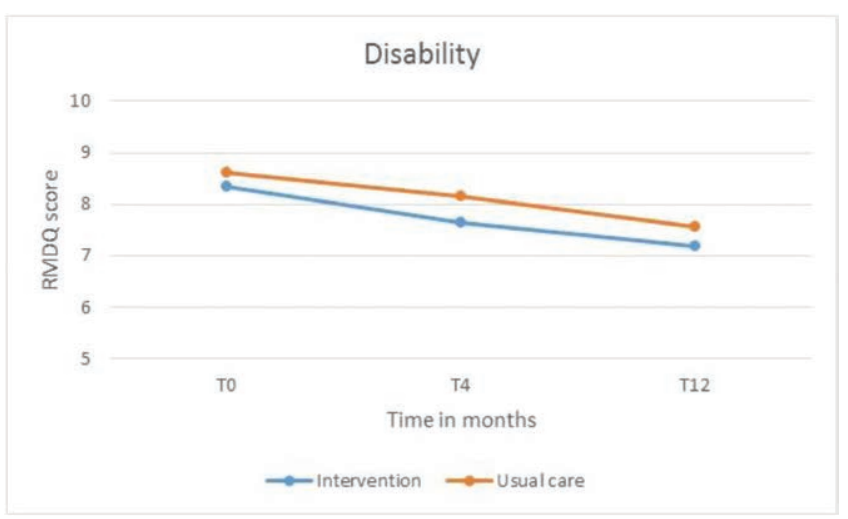

Figure 1. Estimated mean RMDQ scores over time for the overall intervention and usual care group.
Conclusion: Although the functional disability due to pain reduces over time, there was no positive effect by referring based on the CaFaSPA model. Further data on PROMs for the axSpA patients are under investigation.

\section{References:}

[1] Jois RN et al. Rheumatology (Oxford) 2008;47:1364-1366.

[2] van Hoeven L et al. PLoS One 2015; 22;10(7):e0131963.

[2] Moons KG et al. Heart 2012;98(9):691-8.

Disclosure of Interests: None declared

DOI: 10.1136/annrheumdis-2020-eular.6090

\section{OP0280 $\quad$ TEMPORAL TRENDS OF OPIOID USE AMONG INCIDENT OSTEOARTHRITIS PATIENTS IN CATALONIA, 2007-2016: A POPULATION-BASED COHORT STUDY}

J. Xie $^{1}$, A. Turkiewicz ${ }^{2}$, G. Collins ${ }^{3}$, M. Englund ${ }^{4}$, V. Y. Strauss ${ }^{1}$, C. Reyes ${ }^{5}$, D. Prieto-Alhambra ${ }^{1} .{ }^{1}$ University of Oxford, Nuffield Department of Orthopaedics, Rheumatology and Musculoskeletal Sciences, Oxford, United Kingdom; ${ }^{2}$ Lund University, Department of Clinical Sciences Lund, Orthopaedics, Clinical Epidemiology Unit, Lund, Sweden; ${ }^{3}$ University of Oxford, Center for Statistics in Medicine, NDORMS, Oxford, United Kingdom; ${ }^{4}$ Lund University, Department of Clinical Sciences Lund, Orthopaedics, Clinical Epidemiology Unit Institution, Lund Sweden; ${ }^{5}$ IDIAP Jordi Gol, GREMPAL, Barcelona, Spain

Background: Opioids are not recommended as first-line treatments for chronic pain management in osteoarthritis (OA), but recent data suggest they are commonly used in routine practice in North America and northern Europe.

Objectives: To characterise the secular trends of opioid and strong opioids use in patients with incident OA from 2007 to 2016, and to explore the impact of patient characteristics on the use of opioid/s for OA.

Methods: Data was obtained from the SIDIAP (The System for the Developmen of Research in Primary Care) database, which contains primary care records and
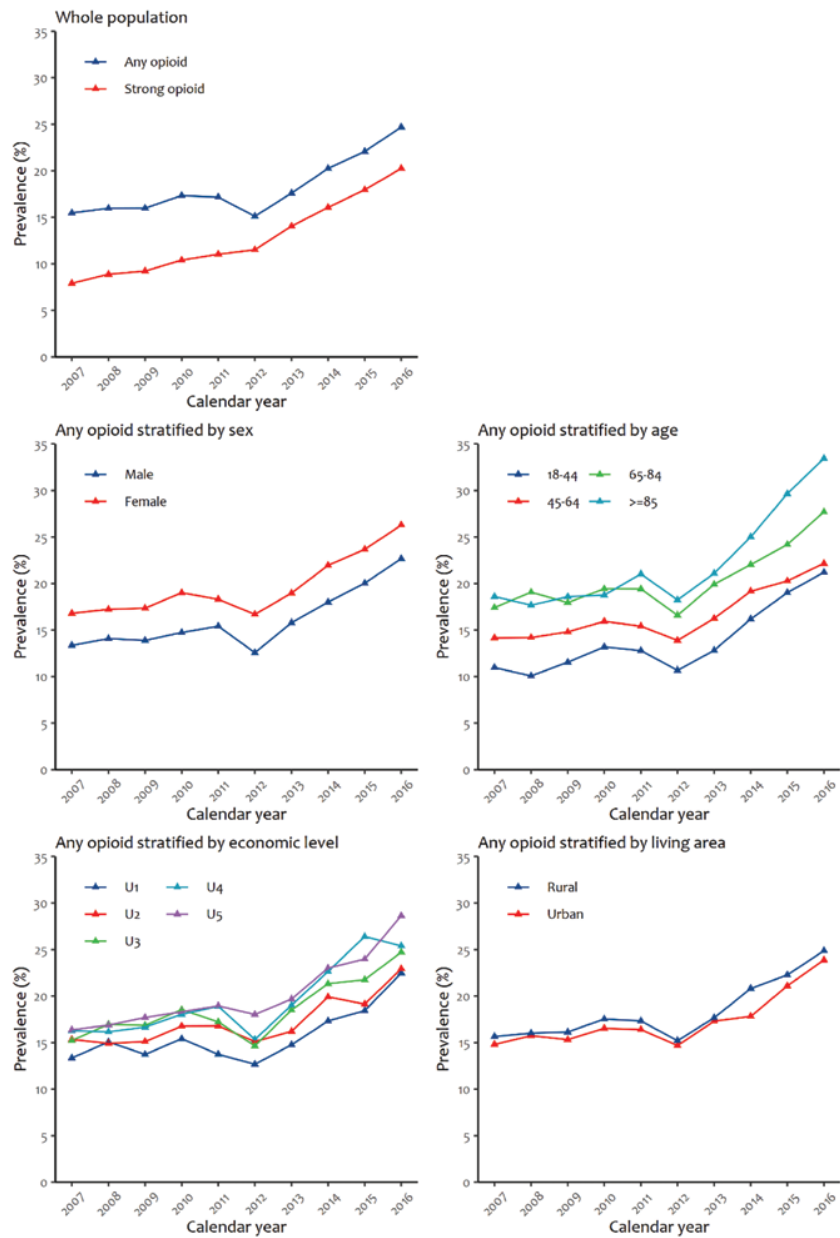

Figure 1. Trends of 1-year prevalence of opioid/s use among incident OA patients, whole and subgroup population. 